\title{
Rosette-forming glioneuronal tumor: a pineal region case with IDH1 and IDH2 mutation analyses and literature review of 43 cases
}

\author{
Orestes E. Solis $\cdot$ Rupal I. Mehta $\cdot$ Albert Lai $\cdot$ Rashi I. Mehta $\cdot$ \\ Lama O. Farchoukh · Richard M. Green · Jerry C. Cheng $\cdot$ Sathima Natarajan • \\ Harry V. Vinters $\cdot$ Timothy Cloughesy $\cdot$ William H. Yong
}

Received: 1 February 2010/ Accepted: 26 July 2010/Published online: 25 September 2010

(C) The Author(s) 2010. This article is published with open access at Springerlink.com

\begin{abstract}
Rosette-forming glioneuronal tumor (RGNT) of the fourth ventricle is a mixed glio-neuronal neoplasm recently codified by the World Health Organization WHO Classification of Central Nervous System (CNS) Tumors (2007). To date, 43 cases have been described in the literature; most occurring in the fourth ventricle region. We report the fourth case involving the pineal region in a 16-year-old female with signs of increased intracranial pressure (ICP). A stereotactic biopsy of the mass was followed by a debulking procedure. Both specimens revealed classic RGNT histology. The patient had stable scans 7 months post-resection. The clinical, radiological and histopathologic features of the previously described 43 cases are reviewed along with our illustrative case. Mean
\end{abstract}

O. E. Solis $(\bowtie) \cdot$ R. I. Mehta · R. I. Mehta ·

H. V. Vinters · W. H. Yong $(\square)$

Department of Pathology and Laboratory Medicine,

Section of Neuropathology, University of California,

Los Angeles, Los Angeles, CA, USA

e-mail: OSolis@mednet.ucla.edu

W. H. Yong

e-mail: WYong@mednet.ucla.edu

R. I. Mehta

e-mail: RMehta@mednet.ucla.edu

R. I. Mehta

e-mail: rmehta2007@gmail.com

H. V. Vinters

e-mail: HVinters@mednet.ucla.edu

A. Lai · T. Cloughesy

Department of Neurology, Neuro-Oncology Program, University

of California, Los Angeles, Los Angeles, CA, USA

e-mail: albertlai@mednet.ucla.edu

T. Cloughesy

e-mail: TCloughesy@mednet.ucla.edu age of patients was $30 \pm 12.8$ years with 1.9:1 female to male ratio. The most common presenting signs related to increased ICP and posterior fossa involvement, including: headache (62.8\%), ataxia (39.5\%) and vomiting and vertigo (both 16.3\%). This tumor usually presents with cystic changes $(54.5 \%)$ with focal enhancement $(60.9 \%)$ and hydrocephalus (43.2\%). Microcalcifications and satellite lesions were common radiographic observations. All reported cases had the classic biphasic pattern. Rosenthal fibers and eosinophilic granular bodies are each present in approximately two thirds of cases. Ki-67 labeling index is consistently low (mean (\%): $1.8 \pm 0.75 \mathrm{SD}$ ). The isocitrate dehydrogenase 1 or 2 mutation found in low grade diffuse gliomas is not identified in this RGNT case. Reported

\section{O. Farchoukh}

Department of Pathology, American University of Beirut

Medical Center, Riad El Solh, Beirut Beirut 1107 2020, Lebanon

e-mail: lama.farchoukh@gmail.com

R. M. Green

Los Angeles Medical Center, Neuro-Oncology Program,

Kaiser Permanente, 4867 W Sunset Blvd.,

Los Angeles, CA 90027, USA

e-mail: richard.m.green@kp.org

J. C. Cheng

Pediatric Hematology-Oncology/Pediatric BMT,

Kaiser Permanente - Los Angeles Medical Center,

4867 W Sunset Blvd., Los Angeles, CA 90027, USA

e-mail: jerry.c.cheng@kp.org

\section{S. Natarajan}

Department of Pathology, Kaiser Permanente - Los Angeles

Medical Center, 4867 W Sunset Blvd., Los Angeles,

CA 90027, USA

e-mail: sathima.x.natarajan@kp.org 
outcome is nearly uniformly excellent after complete or subtotal resection. A solitary report of recurrence after 10 years and the limited experience with this entity suggest that long term follow up is advisable.

Keywords Rosette-forming glioneuronal tumor . Neurocytic rosettes - Glioneuronal tumor - Glioma . Isocitrate dehydrogenase · IDH1 - IDH2 - Fourth ventricle . Pineal

\section{Introduction}

Posterior fossa tumors showing neuronal and glial differentiation, with or without a ganglion component, have been described in recent years [1]. Rosette-forming glioneuronal tumor (RGNT) of the fourth ventricle (WHO grade I), a rare slow growing tumor affecting mainly the young, characterized by distinct neurocytic rosettes or perivascular pseudorosettes and an astrocytic component, is one of the rare benign mixed neuronal-glial neoplasms added in the most recent edition of $\mathrm{WHO}$ Classification of Central Nervous System (CNS) Tumors (2007) [2]. It was first described as a dysembryoplastic neuroepithelial tumor (DNET) of the cerebellum in 1995 [3] and was recognized as a new entity in 2002, largely based on the reports of Komori et al. who extensively described 11 cases [4-6]. RGNT was initially described as occurring solely in the fourth ventricle and with possible extension into the surrounding structures, including the cerebellar vermis, cerebello-pontine angle, midbrain and aqueduct of Sylvius $[4,7,8]$. However, reports of origin from other sites in the CNS, including the pineal region, have been documented [4, 9]. Scheithauer et al. [10] described RGNT in the optic chiasm in a 23-year-old Caucasian male with neurofibromatosis Type 1 (NF1). It was also reported in the cervical spinal cord of a 44-year-old woman [11]. Recently, an unusual widespread intraventricular dissemination of RGNT was described in a 16-year-old Chinese girl with stable outcome 7 months post-radiotherapy [12].

Consistently, reports show a high frequency of somatic isocitrate dehydrogenase 1 (IDH1) and isoform IDH2 mutation among oligodendrogliomas, astrocytomas and secondary glioblastomas [13-21]. This mutation is exceedingly rare in primary glioblastomas and pilocytic astrocytomas, and virtually absent in meningiomas and ependymomas, suggesting a different pathobiological mechanism or stem cell glial precursor. In a limited study, IDH1 mutation in gangliogliomas was reported to be associated with poorer outcome, though IDH1-positive gangliogliomas showed "atypical" features pathologically [20]. Whether these IDH1 mutant cases are diffuse gliomas with overrun neurons remains to be resolved. As RGNT shares some morphologic features with low grade gliomas and gangliogliomas, we carried out deoxyribonucleic acid (DNA) sequencing of IDH1 [residue (R)132] and IDH2 (R172) mutation hotspots to assess whether they also occur in this tumor.

Excluding this case, we identified 19 published papers with 43 diagnosed RGNT cases to date. The prevalence of some clinico-radiologic and histologic findings has not been quantified; hence, it is also the objective of this report to review the frequency of specific radiographic and histologic findings, as well as analyze treatment and outcome from previously-described cases to better elucidate the nature of this rare neoplasm.

\section{Case summary}

A previously healthy 16-year old female presented for chronic episodes of right-sided headaches and vomiting, relieved with rest alone. On physical examination, her pupils were noted to be sluggishly reactive to light and bilateral papilledema was noted. Noncontrast computed tomographic study of the head revealed a mass centered in the pineal gland region with punctate calcification, extending into the posterior aspect of the third ventricle. There was marked associated obstructive hydrocephalus due to mass effect and compression of the cerebral aqueduct. A subsequent cranial magnetic resonance imaging (MRI) with gadolinium further defined a heterogeneous, non- enhancing $3.8 \mathrm{~cm} \times 3.6$ $\mathrm{cm} \times 3 \mathrm{~cm}$ mass in the pineal region, encroaching into the posterior third ventricle (Fig. 1). MRI of the spine showed no metastatic disease. A biopsy of the tumor was performed via endoscopic third ventriculostomy. Tumor markers, including beta-human chorionic gonadotropin, and alpha-fetoprotein were not significantly elevated in both the blood and cerebrospinal fluid (CSF). The pathologic diagnosis was RGNT. The patient was referred for tumor debulking 8 weeks post-biopsy as follow-up MRI revealed increasing hydrocephalus. A suprasellar, infratentorial approach was undertaken and subtotal resection was achieved. Post-operatively, the patient showed significant improvement with no reported complications. Follow-up imaging 2 months postresection revealed a residual mass in the pineal gland region with stable hydrocephalus. Of note, the patient has stable neurologic status and continues to see a pediatric endocrinologist for primary amenorrhea, which may be related to the chronic hydrocephalus.

The review of RGNT cases was carried out through searches in the literature using PubMed queries (up to and including January 2010) for original articles (including reviews) using a combination of the terms rosette forming glioneuronal tumor and RGNT. The cited references of the sources were also searched. The search yielded 30 papers reporting a total of 43 RGNT cases. The pertinent clinical, 

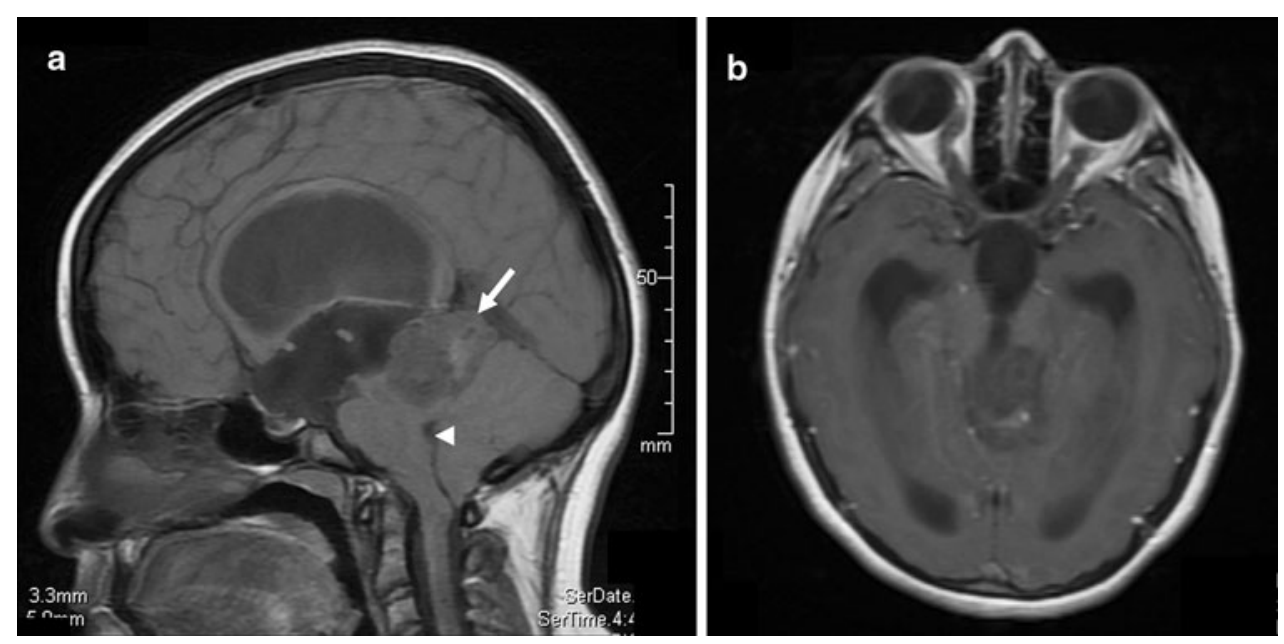

Fig. 1 Preoperative MRI findings. a T1-weighted sagittal MRI shows a heterogenous predominantly isointense to slightly hypointense mass (arrow) centered in the pineal region and extending to the posterior aspect of the third ventricle. There is extensive associated mass effect, including upon the tectum, with effacement of the

radiographic and histological data are presented in tables and further elucidated in the discussion.

\section{Materials and methods}

Histology and immunohistochemistry

Samples were fixed in $10 \%$ neutral formalin and paraffinembedded sections were stained with hematoxylin and eosin for routine light microscopy. Immunohistochemical examinations on 5-micron thick sections were performed on both specimens using BenchMark XT (BMX), utilizing standard avidinbiotin-peroxidase complex technique and diaminobenzidine as chromogen with the following antibodies: glial fibrillary acidic protein (GFAP) (1:200, GF2 clone, monoclonal, DAKO), synaptophysin (Prediluted, 1:100, Ventana), neurofilament (NF) (pre-diluted, 2F11, monoclonal, DAKO), and Ki-67 (1:100, clone MIB-1, monoclonal, DAKO).

IDH1/2 mutation analysis

\section{DNA extraction}

DNA was extracted from the patient's resection specimen (FFPE) using the Recoverall Kit (Applied Biosystems/Ambion, Foster City, CA) according to manufacturer's directions.

\section{Polymerase Chain Reaction (PCR) amplification}

PCR reactions for IDH1 and 2 amplification employed similar methods published elsewhere $[15,18,19]$. An cerebral aqueduct. There is enlargement of the lateral and third ventricles due to obstructive hydrocephalus. Multiple hypointense foci within the tumor may indicate cystic areas. There is no extension of tumor to the fourth ventricle or cerebral aqueduct; $\mathbf{b}$ T1-weighted axial MRI with gadolinium shows no enhancement within the tumor

IDH1 fragment of $237 \mathrm{bp}$ in length spanning the sequence including codon 132 (exon 4) was amplified using forward 5́GCGTCAAATGTGCCACTATC3́and reverse 5-5́GCAA AATCACATTATTGCCAAC3́ primers. An IDH2 fragment of $265 \mathrm{bp}$ in length of IDH2 spanning codon 172 (exon 4) was amplified using forward 5CTCACAGAGTTC AAGCTGAAGAAG3́ and reverse 5́CTGTGGCCTTGTAC TGCAGAG3́ primers. PCR reactions were performed in $30 \mu \mathrm{l}$ volume, including $20 \mathrm{ng}$ of genomic DNA, $10 \mathrm{pmol}$ of each forward and reverse primer above, $1 \times$ PCR buffer, $0.3 \mathrm{mM} \mathrm{dNTP}, 1.5 \mathrm{mM} \mathrm{MgCl} \mathrm{Mn}_{2}$ and 0.5 unit of Platinum Taq (Invitrogen, Carlsbad, CA). PCR conditions were: $94^{\circ} \mathrm{C}$ for $1 \mathrm{~min}$ and $30 \mathrm{~s} ; 5$ cycles of $94^{\circ} \mathrm{C}$ for $20 \mathrm{~s}, 65^{\circ} \mathrm{C}$ for $20 \mathrm{~s}, 72^{\circ} \mathrm{C}$ for $20 \mathrm{~s} ; 5$ cycles of $94^{\circ} \mathrm{C}$ for $20 \mathrm{~s}, 60^{\circ} \mathrm{C}$ for $20 \mathrm{~s}, 72^{\circ} \mathrm{C}$ for $20 \mathrm{~s} ; 5$ cycles of $94^{\circ} \mathrm{C}$ for $20 \mathrm{~s}, 55^{\circ} \mathrm{C}$ for $20 \mathrm{~s}, 72^{\circ} \mathrm{C}$ for $20 \mathrm{~s}$; and 30 cycles of $94^{\circ} \mathrm{C}$ for $20 \mathrm{~s}, 50^{\circ} \mathrm{C}$ for $20 \mathrm{~s}, 72^{\circ} \mathrm{C}$ for $20 \mathrm{~s}$, followed by $72^{\circ} \mathrm{C}$ for $10 \mathrm{~min} .6 \mu \mathrm{l}$ of PCR product was loaded on a $2 \%$ agarose gel and visualized under UV light.

\section{Sequencing detection}

The PCR products were purified using DNA Clean \& Concentrator Kit (Zymo Research, Orange, CA). 10 ng of purified PCR product was used for sequencing reaction with total volume of $10 \mu \mathrm{l}$, containing $1.6 \mathrm{pmol}$ of sequencing primers (IDH1 5́GCGTCAAATGTGCCACTATC $3 ́$ and IDH2 5́CTCACAGAGTTCAAGCTGAAGAAG3́), 1× sequencing buffer, $1.5 \mu \mathrm{l}$ of BigDye Terminator v1.1(Applied Biosystems, Foster City, CA). Sequencing conditions were: $96^{\circ} \mathrm{C}$ for $1 \mathrm{~min}$, followed by 25 cycles of $96^{\circ} \mathrm{C}$ for $10 \mathrm{~s}, 50^{\circ} \mathrm{C}$ for $5 \mathrm{~s}$ and $60^{\circ} \mathrm{C}$ for $4 \mathrm{~min}$. The sequencing reactions were purified 
using Performa DTR Gel Filtration Cartridges (Edge Bio, Gaithersburg, MD) and analyzed on a 3730 sequencer (Applied Biosystems) maintained by the UCLA Sequencing Core.

\section{Results}

Histology and immunohistochemistry

Histologic examination of both biopsy and resection specimens revealed a biphasic, moderately cellular neoplasm (Fig. 2). The lesion was composed of a synaptophysin immunoreactive neurocytic component characterized by monomorphic cells with round hyperchromatic nuclei and scant cytoplasm forming rosettes and perivascular pseudorosettes, and an extensively GFAP positive piloid glial area similar to that in previously described RGNTs [2-12,
22-29]. Synaptophysin immunoreactivity was also noted in the eosinophilic cores of rosettes and perivascular rosettes formed by bland neurocytes. In areas of the glial component, tumor cells arranged in cords and packets with frequent peri-cellular halos resembling an oligodendroglioma were found. Focal microcalcifications were identified. Rosenthal fibers, eosinophilic granular bodies (EGBs), mitoses, necroses and vascular endothelial hyperplasia were not identified. Ki67 immunostain revealed a low proliferation index estimated at approximately $1 \%$ or less. Chromogranin stain was largely negative and did not reveal neoplastic ganglion cells.

\section{IDH1 and 2 mutation analyses}

IDH analysis of this tumor showed wild type genetic sequences in exon 4 of both IDH1 (R132) and IDH2 (R172) genes.
Fig. 2 Histologic features: a Low power microscopy reveals a biphasic tumor with neurocytic (right) and astrocytic (left) components, H\&E, $\times 200$; b Well-formed perivascular rosettes and true rosettes (inset), $\mathrm{H} \& \mathrm{E}, \times 1,000$; c Strong synaptophysin staining is noted among neurocytes and neurocytic cores, $\times 400$; d High power view of the synaptophysin-positive neurocytic cores, $\times 1,000$; e Glial fibrillary acidic protein immunostain highlights the piloid astrocytic component, $\times 200$; and $\mathbf{f}$ Collections of oligodendrocyte-like cells are present, $\mathrm{H} \& \mathrm{E}, \times 400$

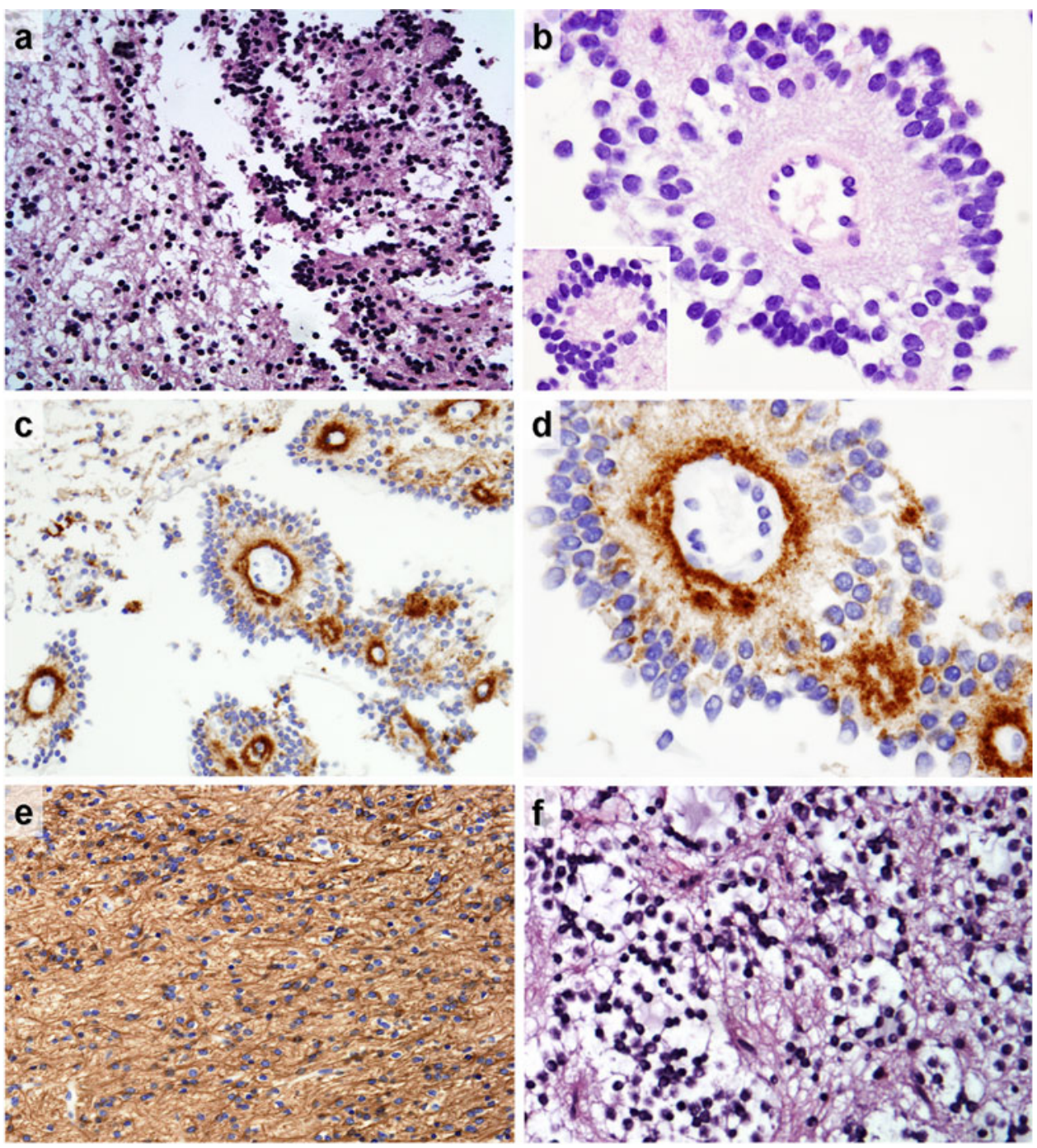




\section{Discussion}

Epidemiology of this neoplasm is limited since there are relatively few published cases. In our review (Fig. 3), this tumor was found to more commonly afflict young adults (mean: $30 \pm 12.8$ years ), with nearly a two-fold female predominance (1.9:1 female to male ratio), which is similar to earlier findings [4, 24, 29].

The clinico-radiologic characteristics in our patient are similar to those previously described. However, this tumor largely involves the pineal region, abuts the posterior third ventricle and impinges on the cerebral aqueduct causing hydrocephalus, which is a less common observation. Table 1 summarizes the clinical findings from previously published data. Our patient presented with headache and vomiting which are still the most commonly reported symptoms in the review (Table 2). Ataxia (39.5\%), vertigo $(16.3 \%)$, cranial nerve palsies $(13.2 \%)$ and visual complaints $(11.6 \%)$, are also commonly observed. Signs and symptoms appear to be related to the common location of this tumor (see Table 1) which is the fourth ventricle $(31.8 \%)$ and contiguous structures $(25 \%)$, and are related to posterior fossa involvement and early development of obstructive hydrocephalus from CSF flow interruption in the fourth ventricle. $\mathrm{Li}$ et al. [25] reported intratumoral hemorrhage in one patient leading to incidental diagnosis, along with five other cases that did not have apparent symptoms $(14 \%)$.

Paramount concern among studies of "new" tumor entities is in regard to their natural history. This tumor appears to have a variable growth pattern. Available data in 32 cases (Table 1) show an extremely large gap in the reported duration of symptoms, ranging from a few hours to 15 years from the first report of neurologic disturbance (mean duration: $27.2 \pm 44.6$ months). One patient [7] presented acutely in the emergency room secondary to intratumoral

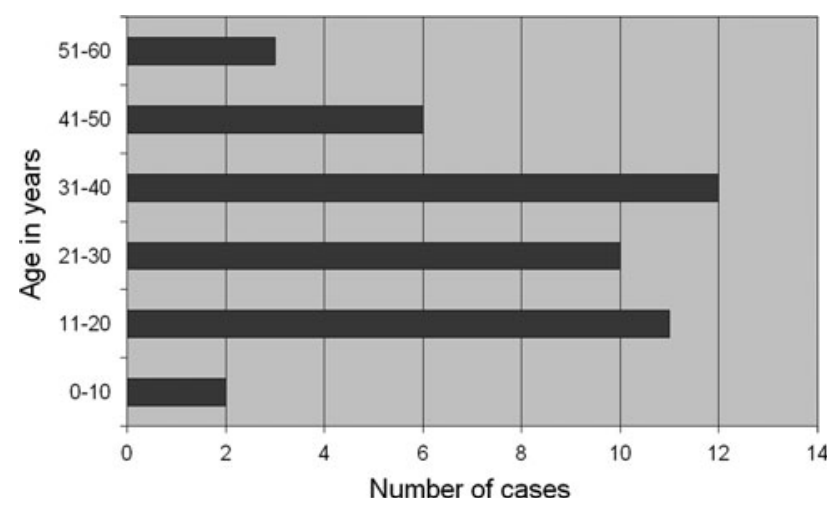

Fig. 3 Age distribution of rosette-forming glioneuronal tumor cases showing predominantly younger age group (11-40 age bracket). The mean age at presentation is $30.3 \pm 12.8$ years with 1.9:1 female to male ratio
Table 1 Summary of clinical and radiological features of rosetteforming glioneuronal tumor cases

\begin{tabular}{|c|c|}
\hline \multicolumn{2}{|l|}{ Patient demographics } \\
\hline Age in years, mean (SD) & $30.3( \pm 12.8)$ \\
\hline \multicolumn{2}{|l|}{ Gender, $n(\%)$} \\
\hline Male & $15 / 44(39.5)$ \\
\hline Female & $29 / 44(60.5)$ \\
\hline Duration in months, mean (SD) & $27.2( \pm 44.8)$ \\
\hline \multicolumn{2}{|l|}{ Treatment, $n(\%)$} \\
\hline GTR & $25 / 44(56.8)$ \\
\hline STR & $15 / 44(34.1)$ \\
\hline Biopsy & $5 / 44(11.4)$ \\
\hline Radiotherapy & $2 / 44(4.5)$ \\
\hline \multicolumn{2}{|l|}{ Post-op morbidity, $n(\%)$} \\
\hline Yes & $13 / 35(37.1)$ \\
\hline $\mathrm{No}^{\mathrm{a}}$ & $23 / 35(65.7)$ \\
\hline Follow-up in months, mean (SD) & $30.2( \pm 35.7)$ \\
\hline \multicolumn{2}{|l|}{ Outcome, $n(\%)$} \\
\hline Stable & 29/35 (94.3) \\
\hline Death & $1 / 35$ \\
\hline Recurrence & $1 / 35$ \\
\hline \multicolumn{2}{|l|}{ Radiologic features } \\
\hline \multicolumn{2}{|l|}{ Location, $n(\%)$} \\
\hline Fourth ventricle+ & $25 / 44(56.8)$ \\
\hline Cerebellum & $10 / 44(22.7)$ \\
\hline Pineal & $4 / 44(9.1)$ \\
\hline Others & $5 / 44(11.4)$ \\
\hline Size in mm, mean (SD) & $30.3( \pm 16.8)$ \\
\hline \multicolumn{2}{|l|}{ Findings, $n(\%)$} \\
\hline Enhancement & $29 / 44(65.9)$ \\
\hline Cyst & $24 / 44(52.5)$ \\
\hline Hydrocephalus & $19 / 44(43.2)$ \\
\hline Calcification & $11 / 44(25)$ \\
\hline Satellite lesion & $7 / 44(15.9)$ \\
\hline
\end{tabular}

$S D$ standard deviation, NA data not available, GTR gross total resection, $S R T$ subtotal resection. Fourth ventricle+ refers to tumor originating from or centered in the fourth ventricle with involvement of the contiguous structures

a Transient symptoms were included

bleeding, which led to sudden obstructive hydrocephalus. A plausible explanation is that this tumor might have an extremely indolent growth that patients do not recognize or report symptoms, except in cases of inherent tumoral complications (e.g. infarction, hemorrhage). The brain MRIs show most consistently solid-cystic changes $(54.5 \%)$ that are iso/hypointense on T1-weighted images and hyperintense on T2-weighted images and with high probability of enhancement (whether ring-enhancement or heterogenous pattern, $65.9 \%$; Table 1). Average size was $30.3 \pm 16.8 \mathrm{~mm}$ in the 29 cases with available information. Eleven patients $(25 \%)$ showed calcifications while satellite lesions were noted in 
Table 2 Frequency of signs and symptoms observed in rosetteforming glioneuronal tumor cases

\begin{tabular}{lc}
\hline Signs and symptoms & Frequency $(\%)$ \\
\hline Headache & $27(62.8)$ \\
Ataxia & $17(39.5)$ \\
Vertigo & $7(16.3)$ \\
Nausea/vomiting & $7(16.3)$ \\
Cranial nerve palsy & $6(14.0)$ \\
Incidental & $6(14.6)$ \\
Visual complaints & $5(11.6)$ \\
Motor sensory & $4(9.3)$ \\
Dysarthria & $3(7.0)$ \\
Seizure & $1(2.3)$ \\
Nystagmus & $1(2.3)$ \\
Hyperacussis & $1(2.3)$ \\
\hline
\end{tabular}

seven patients. Multiple lesions were extremely rare occurrences.

RGNT is a newly recognized CNS tumor having biphasic histologic characteristics [1, 30, 31]. The key features [2], described in virtually all the reports, include: (i) a neurocytic component composed of neurocytes forming rosettes (resembling Homer-Wright rosettes) around a synaptophysin-positive eosinophilic core and/or perivascular pseudorosettes that are arranged in arrays towards a vessel and (ii) an astrocytic component that is frequently described as closely resembling that of a pilocytic astrocytoma. A microcystic, myxoid matrix may be found in these neurocytic structures, while oligodendroglia-like cells (OLCs) may be seen in areas of the glial component. It has been reported that these OLCs have strong synaptophysin and Olig2 reactivity; however, they do not show $1 \mathrm{p} / 19 \mathrm{q}$ co-deletion [12]. Olig2, a transcription factor that controls development and differentiation of oligodendrocytes, is known to have variable expression in oligodendrocytes, oligodendrogliomas, neuroepithelial tumors and other glioneuronal tumors [32-34]. In our review, Rosenthal fibers and EGBs are each present in over $60 \%$ of cases. Nearly $1 / 2$ of cases have hyalinized blood vessels and myxoid stroma. In $1 / 3$ of cases microcalcifications are noted (Table 3 ). "Dysmorphic" ganglion cells are reported in five cases [4, 5]. "Floating" Purkinje cells are specified in three cases [3, 29]. Whether the reported "dysmorphic" ganglion cells are also "floating" Purkinje cells remain to be clarified. Mitoses and necrosis are generally absent. No ganglion cells were identified in our illustrative case. Neither the neurocytic nor the astrocytic cellular component shows atypia.

The immunohistochemical profile in our case is compatible with the previously published cases. Consistently described is immunoreactivity for synaptophysin in the
Table 3 Additional histologic features seen in rosette-forming glioneuronal tumor cases

\begin{tabular}{lc}
\hline Pathologic finding & Frequency $(\%)$ \\
\hline Rosenthal fibers & $29(65.9)$ \\
Eosinophilic granular bodies & $24(64.5)$ \\
Myxoid stroma & $21(47.7)$ \\
Hyalinized vessels & $19(43.2)$ \\
Microcalcification & $13(29.5)$ \\
Neurons & $9(20.4)$ \\
Hemorrhage & $5(11.4)$ \\
Hemosiderin & $4(9.1)$ \\
Vascular endothelial hyperplasia & $4(9.1)$ \\
\hline
\end{tabular}

neurocytic rosettes and perivascular pseudorosettes. Microtubule associated protein 2 (MAP2) and neuron specific enolase have also been reported to be expressed in the neurocytic cell processes. GFAP and S-100 immunoreactivity are variably present in the glial component, but are absent in the neurocytic component. Ki-67 labelling index is generally low, similar to the observation in our case $(<1 \%)$. Review of cases with available information shows a mean Ki-67 index of $1.8 \pm 0.75$ (SD) (range: 0-3.8\%).

RGNTs have been suggested to arise from cells of the subependymal plate (periventricular germinal matrix) [4] which have also been suggested as the site of origin of DNETs of the cerebellum [1]. Whether this finding reflects normal or aberrant developmental placement of precursor or stem cells is uncertain. Increasing numbers of RGNTs have been recognized in locations other than the fourth ventricle. The alternate possibility of histologically similar tumors with underlying genetic differences is not excluded.

\section{Genetics of RGNT}

Genetic abnormalities have not been well characterized in RGNT though they have been found in other glioneuronal tumors [35-38]. Due to very limited sample tissue availability in this case and given that chromosomes $1 \mathrm{p} / 19 \mathrm{q}$ and Olig2 gene have been previously studied, we chose only to evaluate for IDH1 and 2 mutations.

IDH1 is a gene encoding cytosolic NADP + -dependent isocitrate dehydrogenase, an enzyme that catalyzes oxidative decarboxylation of isocitrate to alpha-ketoglutarate. A hotspot mutation is located at position 395 (R132). R172 in exon 4 of IDH2 has the analogous function of R132 of IDH1 and is similarly a mutational hotspot in the gene. It is also suggested that $I D H$ mutation is an early marker for tumorigenesis of diffuse gliomas as it tends to occur earlier than mutation of other genes including TP53, PTEN, and EGFR [14, 15], but is non-existent or rare in other types of brain tumors including gangliogliomas. 
To date, genetic studies performed on RGNT is limited to evaluation for $1 \mathrm{p} 19 \mathrm{q}$ loss [12] and neurofibromatosis type 1 (NF1) gene deletion in chromosome 17 [10] by fluorescent in situ hybridization; both of which were intact in this low grade neoplasm. Our finding of wild type IDH1 and IDH2 genotypes in RGNT are consistent with prior observations that mutations of those genes are relatively specific for diffuse gliomas. Nevertheless, more work is required to establish whether this finding is typical of RGNT in general or pertinent to pineal RGNTs only.

\section{Treatment and prognosis}

The benign nature of this tumor has been repeatedly documented in most published studies. Despite a sizable number of cases (43 documented), gross total or subtotal resection (56.8\% and $34 \%$ of cases respectively) appears to be effective in treating this tumor, with excellent outcome and with relatively little post-operative morbidity (Table 1). Even patients who underwent biopsy alone remained stable with 1-2 year follow up [8]. The majority of the cases did well post-operatively, with over a half of the cases $(51.4 \%)$ having an unremarkable course or transient symptoms $(14.3 \%)$. Documented post-operative morbidities include: ataxia (20\%), cranial nerve palsy $(17.1 \%)$ and othersincluding isolated cases of dysmetria, dysphagia, mutism, aggravation of presenting symptoms, and amenorrhea (in our case, which was likely a complication of chronic hydrocephalus). One patient who presented with disseminated intraventricular RGNT [12] was stable after radiotherapy (46 Gy). One patient [4], after subtotal resection and radiotherapy (5,500 cGy), died after 4 years, shortly after developing progressive brainstem symptoms and a ring enhancing lesion near the operative site. However, no autopsy was performed and the lesion was attributed to brainstem "radionecrosis". Only one case out of 35 (2.9\%) with follow up recurred and did so after 10 years (mean follow-up (months): $30.3 \pm 35.6$ ) —see Table 1. Apart from post-surgical changes, the recurrence showed the typical RGNT histology. The value of treatment with radiation of RGNT is unclear owing to the scarcity of treated cases.

\section{Conclusion}

RGNT of the fourth ventricle is a distinct tumor entity that also arises in other locations of the CNS. Whether the tumor should be renamed will likely be a source of debate. The presence of Rosenthal fibers and EGBs in a piloid neoplasm involving the fourth ventricle or pineal region should prompt consideration of RGNT and a search for the typical neurocytic areas. We identify wildtype IDH1 and
IDH2 genes but additional cases would be helpful to confirm this not unexpected genotype in RGNT. It should certainly be considered in the radiological differential diagnosis of solid-cystic tumors of the posterior fossa showing variable enhancement, with or without calcification. While the course is nearly always benign, the rare case of recurrence suggests that long-term follow up may be desirable.

Acknowledgments H.V.V \& O.E.S. supported in part by the Daljit S. \& Elaine Sarkaria Chair in Diagnostic Medicine. W.H.Y. \& T.F.C. supported in part by the Art of the Brain and the Henry Singleton Brain Tumor Fund.We thank Weidong Chen of the UCLA Department of Neurology and the personnel at the Brain Tumor Translational Resource for their invaluable assistance to the project.

\section{Conflict of interest None.}

Open Access This article is distributed under the terms of the Creative Commons Attribution Noncommercial License which permits any noncommercial use, distribution, and reproduction in any medium, provided the original author(s) and source are credited.

\section{References}

1. Allende DS, Prayson RA (2009) The expanding family of glioneuronal tumors. Adv Anat Pathol 16:33-39

2. Hainfellner JA, Scheithauer BW, Giangaspero F, Rosenblum MK (2007) Rosette-forming glioneuronal tumour of the fourth ventricle. In: Louis DN, Ohgaki H, Wiestler OD, Cavenee WK (eds) WHO classification of tumours of the central nervous system. IARC, Lyon, pp 115-116

3. Kuchelmeister K, Demirel T, Schlörer E et al (1995) Dysembryoplastic neuroepithelial tumour of the cerebellum. Acta Neuropathol (Berl) 89:385-390

4. Komori T, Scheithauer BW, Hirose T (2002) A rosette-forming glioneuronal tumor of the fourth ventricle: infratentorial form of dysembryoplastic neuroepithelial tumor? Am J Surg Pathol 26: 582-591

5. Preusser M, Dietrich W, Czech T et al (2003) Rosette-forming glioneuronal tumor of the fourth ventricle. Acta Neuropathol (Berl) 106:506-508

6. Albanese A, Mangiola A, Pompucci A et al (2005) Rosetteforming glioneuronal tumour of the fourth ventricle: report of a case with clinical and surgical implications. J Neurooncol 71: 195-197

7. Marhold F, Preusser M, Dietrich W et al (2008) Clinicoradiological features of rosette-forming glioneuronal tumor (RGNT) of the fourth ventricle: report of four cases and literature review. J Neurooncol 90:301-308

8. Tan CC, Gonzales M, Veitch A (2008) Clinical implications of the infratentorial rosette-forming glioneuronal tumor: case report. Neurosurgery 63:E175-E176

9. Jacques TS, Eldridge C, Patel A et al (2006) Mixed glioneuronal tumour of the fourth ventricle with prominent rosette formation. Neuropathol Appl Neurobiol 32:217-220

10. Scheithauer BW, Silva AI, Ketterling RP et al (2009) Rosette forming glioneuronal tumor: report of a chiasmal-optic nerve example in neurofibromatosis type 1: special pathology report. Neurosurgery 64:E771-E772 
11. Anan M, Inoue R, Ishii K et al (2009) A rosette-forming glioneuronal tumor of the spinal cord: the first case of a rosette-forming glioneuronal tumor originating from the spinal cord. Hum Pathol 40:898-901

12. Wang Y, Xiong J, Chu SG et al (2009) Rosette-forming glioneuronal tumor: report of an unusual case with intraventricular dissemination. Acta Neuropathol doi: 10.1007/s00401-009-05 69-1

13. Balss J, Meyer J, Mueller W et al (2008) Analysis of the IDH1 codon 132 mutation in brain tumors. Acta Neuropathol 116(6): 597-602

14. Watanabe T, Vital A, Nobusawa S, Kleihues P, Ohgaki H (2009) IDH1 mutations are early events in the development of astrocytomas and oligodendrogliomas. Acta Neuropathol 117(6):653-656

15. Yan H, Parsons DW, Jin G et al (2009) IDH1 and IDH2 mutations in gliomas. N Engl J Med 360(8):765-773

16. Korshonuv A, Meyer J, Capper D et al (2009) Combined molecular analysis of BRAF and IDH1 distinguishes pilocytic astrocytoma from diffuse astrocytoma. Acta Neuropathol 118(3): 401-405

17. Hartmann C, Meyer J, Balss J et al (2009) Type and frequency of IDH1 and IDH2 mutations are related to astrocytic and oligodendroglial differentiation and age: a study of 1,010 diffuse gliomas. Acta Neuropathol 118(4):469-474

18. Ichimura K, Pearson DM, Kocialkowski L et al (2009) IDH1 mutations are present in the majority of common adult gliomas but rare in primary glioblastoma. Neuro Oncol 11:341-347

19. Parsons DW, Jones S, Zhang X et al (2008) An integrated genomic analysis of human glioblastoma multiforme. Science 321:1807-1812

20. Horbinski C, Kofler J, Kelly LM et al (2009) Diagnostic use of IDH1/2 mutation analysis in routine clinical testing of formalinfixed, paraffin-embedded glioma tissues. J Neuropathol Exp Neurol 68:1319-1325

21. Sonoda Y, Toshihiro K, Nakamura T et al (2009) Analysis of IDH1 and IDH2 mutations in Japanese gliomas patients. Cancer Sci 100:1996-1998

22. Ghosal N, Furtado SV, Hegde AS (2009) Rosette forming glioneuronal tumor pineal gland and tectum: an intraoperative diagnosis on smear preparation. Diagn Cytopathol doi: 10.1002/dc. 21269

23. Kinno M, Ishizawa K, Shimada S et al (2009) Cytology is a useful tool for the diagnosis of rosette-forming glioneuronal tumour of the fourth ventricle: a report of two cases. Cytopathology doi: 10.1111/ j.1365-2303.2008.00619

24. Johnson M, Pace J, Burroughs JF (2006) Fourth ventricle rosetteforming glioneuronal tumor: case report. J Neurosurg 105: 129-131

25. Li YM, Li WQ, Pan Y et al (2009) Rosette-forming glioneuronal tumor of the fourth ventricle with previous intratumoural hemorrhage: case report and review of literature. J Int Med Res 37(3): 958-966

26. Adachi J, Nishikawa R, Hirose T et al (2005) Mixed neuronal glial tumor of the fourth ventricle and successful treatment of postoperative mutism with bromocriptine: case report. Surg Neurol 63: 375-379

27. Pimentel J, Resende M, Vaz A et al (2008) Rosette-forming glioneuronal tumor: pathology case report. Neurosurgery 62: E1162-E1163

28. Vajtai I, Arnold M, Kappeler A et al (2007) Rosette-forming glioneuronal tumor of the fourth ventricle: report of two cases with a differential diagnostic overview. Pathol Res Pract 203: 613-619

29. Shah MN, Leonard JR, Perry A (2010) Rosette-forming glioneuronal tumors of the posterior fossa. J Neurosurg Pediatrics 5: 98-103

30. Louis DN, Ohgaki H, Wiestler OD et al (2007) The 2007 WHO classification of tumours of the central nervous system. Acta Neuropathol (Berl) 114:97-109

31. Rosenblum MK (2007) The 2007 WHO classification of nervous system tumors: newly recognized members of the mixed glioneuronal group. Brain Pathol 17:308-313

32. Fujisawa H, Marukawa K, Hasegawa M et al (2002) Genetic differences between neurocytoma and dysembryoplastic neuroepithelial tumor and oligodendroglial tumors. J Neurosurg 97:1350-1355

33. Ligon K, Alberta JA, Kho AT et al (2004) The oligodendroglial lineage marker OLIG2 is universally expressed in diffuse gliomas. J Neuropathol Exp Neurol 63:499-509

34. Takei H, Yogeswaren ST, Wong KK et al (2008) Expression of oligodendroglial differentiation markers in pilocytic astrocytomas identifies two clinical subsets and shows a significant correlation with proliferation index and progression free survival. J Neurooncol 86:183-190

35. Joseph V, Wells A, Kuo YH et al (2008) The 'rosette-forming glioneuronal tumor' of the fourth ventricle. Neuropathology 29(3): 309-314

36. Perry A, Scheithauer BW, Macaulay RJB et al (2002) Oligodendrogliomas neurocytic differentiation. A report of 4 cases with diagnostic and histogenetic implications. J Neuropathol Exp Neurol 61:947-955

37. Keyvani K, Rickert CH, von Wild K et al (2001) Rosetted glioneuronal tumor: a case with proliferating neuronal nodules. Acta Neuropathol (Berl) 101:525-528

38. Gessi M, Marani C, Geddes J et al (2005) Ependymoma with neuropil-like islands: a case report with diagnostic and histogenetic implications. Acta Neuropathol (Berl) 109:231-234 